\title{
EDUCAÇÃO POPULAR, SAÚDE E INCLUSÃO SOCIAL NA PERSPECTIVA FREIREANA: UMA REVISÃO NARRATIVA
}

\author{
1, ${ }^{*}$ Leandro Alcasar Rodrigues and ${ }^{2}$ Márcia Isabel Gentil Diniz
}

1Professor na Área de Humanas na Faculdade de Educação São Luís. Professor de Geografia e História na Rede Municipal de Jardinópolis-SP. Doutorando em Humanidades e Artes com menção em Ciências da Educação na Universidad Nacional de Rosário - UNR, Argentina. Cursando Especialização em Saúde Coletiva na SOBRESP -

Faculdade de Ciências da Saúde. Pesquisador do Núcleo de Pesquisa e Extensão em Educação e Saúde Comunitária. NUPEESC Brasil. UFF/CNPq. Pesquisador do Núcleo de Pesquisa em Instâncias de Socialização, Políticas Públicas e Movimentos Sociais (Polis-UFF/CNPq). Membro Activo da RedDOLAC - Red de Docentes de América Latina y del Caribe. ${ }^{2}$ Professora Adjunto IV na Universidade Federal Fluminense UFF-RJ. Doutoranda em Humanidades e Artes com menção em Ciências da Educação na Universidad Nacional de Rosário - UNR, Argentina. Líder e pesquisadora do Núcleo de Pesquisa e Extensão em Educação e Saúde Comunitária. NUPEESC

Brasil. UFF/CNPq. Pesquisadora do Núcleo de Pesquisa em Instâncias de Socialização, Políticas Públicas e Movimentos Sociais (Polis-UFF/CNPq). Membro Activo da RedDOLAC - Red de Docentes de América Latina y del Caribe

\section{ARTICLE INFO}

Article History:

Received $17^{\text {th }}$ February, 2021

Received in revised form

$06^{\text {th }}$ March, 2021

Accepted $11^{\text {th }}$ April, 2021

Published online $30^{\text {th }}$ May, 2021

Key Words:

Educação popular,

Bem-estar social, Saúde,

Movimentos sociais

*Corresponding author:

Leandro Alcasar Rodrigues

\begin{abstract}
RESUMO
O artigo é uma análise sobre a educação popular no qual se busca evidenciar diversas inquietações que se encontram diretamente atreladas e voltadas para a busca da saúde, bem estar e inclusão social na perspectiva basilar das diversas obras do educador Paulo Freire, assim como em outros estudiosos que já se debruçaram sobre tal temática.Objetivo: Analisar os sentidos e significados da educação popular e sua potencialidade por um equitativo bem-estar social. Método: uma revisão narrativa com análises fundamentadas no referencial da pedagogia crítica, com pesquisas bibliográficas nas diversas obras pertinentes que se reportam a temática aqui discutida. Analise e Discussão: A educação popular tem sido uma pauta de debates tanto no interior quanto fora do espaço escolar, enquanto movimento educativo contrário à ordem societária vigente de caráter controlador e repressivo, vai além, é uma concepção educacional que implica em diversos pontos de vista críticas com dimensões política, epistemológica, antropológica-ontológica, social, filosófica e ética. Considerações Finais: Os postulados freireanos tiveram um papel fundamental na atividade educativa gerada pelas atividades nos anos 70 e parte dos anos 80 que acreditam ate a atualidade e investem na construção de um conhecimento dialético e educativo.
\end{abstract}

Copyright (C) 2021, Leandro Alcasar Rodrigues and Márcia Isabel Gentil Diniz. This is an open access article distributed under the Creative Commons Attribution License, which permits unrestricted use, distribution, and reproduction in any medium, provided the original work is properly cited.

Citation: Leandro Alcasar Rodrigues and Márcia Isabel Gentil Diniz. 2021. "Educação Popular, Saúde e Inclusão Social na perspectiva Freireana: Uma revisão narrativa”, international journal of development research, 11, (05), 47089-47092.

\section{INTRODUÇÃO}

O trabalho educativo de formação de lideranças provocou também inúmeras iniciativas populares que colaboraram para a organização das massas populares, especialmente urbanas, tais como: rádios comunitárias, bibliotecas populares, centros culturais de bairros, grupos de teatro amadores, inúmeros cursos de formação em centros populares e operários, boletins e uma variada gama de mídia alternativa e concursos populares, e Et Cetera. Nos anos 70, este plano teve um espaço privilegiado para seu desenvolvimento, a saber: as ações das comunidades eclesiais de base cristãs. A Educação Popular era vista como parte integrante do processo organizativo das classes e camadas populares, que era desenvolvido pela Igreja, clero, e sobretudo pelas Comunidades Eclesiais de Base, conhecidas como CEBs, que constituíam em políticas novas, e não somente uma empreitada dos partidos e sindicatos. Ao contrário, em alguns casos 
havia tensão e conflitos entre os programas de alguns partidos de esquerda - considerados como radicais - e as novas organizações populares, mais afeitas às orientações cristãs-neomarxistas ou socialistas-libertárias (GOHN, 1997). Solidificaram também, neste período, vários movimentos e organizações de inspiração religiosa, pastorais sociais, bem como os Centros de Educação Popular e as Organizações Não Governamentais (ONGs). Para se compreender os movimentos sociais, mais do que pensar em valores e crenças comuns para a ação social coletiva, seria necessário analisar as estruturas sociais nas quais os movimentos se manifestam nas relações sociais, de saúde, através das Pastorais, inclusive da Pastoral da Criança e sua ligação com os Postos de Saúde no interior do Brasil, a depender dos modelos culturais, políticos e sociais. Os Movimentos Sociais Populares surgiram no contexto social e político brasileiro com uma arrebatadora capacidade criativa, organizativa e mobilizadora, principalmente na década de 1980, sendo responsáveis por expressivas conquistas que afiançam melhorias na qualidade de vida de amplos setores sociais, afirmação de direitos e exercício da cidadania para um número cada vez maior de aglomerações humanas, construção de identidades coletivas e autoestima pessoal e social de setores e grupos historicamente discriminados ou oprimidos, intervenção nas políticas públicas, modificando ou inibindo as seculares práticas assistencialistas e clientelistas, colaborando assim para mudanças em nível do poder local e da política tradicional. De acordo com Freire (1987) as conjunturas entendidas pelos indivíduos como inevitáveis, representadas da vida em sociedade, construídas sob a pretensa normatividade. As situações-limite podem, dessa forma, serem entendidas também como a invisibilidade histórica de alguns grupos sociais, no caso, as mulheres. Como situações-limite percebemos o patriarcado e diversos outros sistemas de opressão como o racismo e o capitalismo, entre outros. Para suplantarmos esses sistemas, e em especial no caso do patriarcado, precisamos fomentar de diferentes formas o que Freire chamou de percebido destacado, que é o desencadeamento desse processo de consciência. Esse caminho percorrido resultará no inédito-viável, que é a construção efetiva para a transformação do que antes era natural e inevitável - a opressão - em finitude possível e, assim, o que se torna de fato inevitável é o enfrentamento. É transpor a barreira do ser para o ser mais (FREIRE, 2001). Sendo assim, com a base dessa proposta imersa na pedagogia do oprimido é que, necessitamos então, a partir da caracterização do mundo patriarcal, enfrentá-lo. Isto posto, qualquer discussão sobre movimentos sociais não escapa do questionamento recorrente: afinal, o que são movimentos sociais? Diferentemente de outros conceitos, este, em particular, apresenta significados distintos, conforme a concepção a partir da qual se desenvolve.

Os indivíduos que integram nossa sociedade possuem necessidades inseridas em realidades diferentes. Essas necessidades precisam ser representadas em nosso contexto político para que sejam atendidas. A esse respeito Werneck $(1989$, p.61) elucida que: Educar é difícil, trabalhoso, exige dedicação, sobretudo aos que mais necessitam. Transferir problemas é fugir da verdadeira educação, é uma espécie de médico que transfere o doente de hospital, lava as suas mãos e não se sente comprometido com o caso quando da morte do paciente, porque aconteceu em outro hospital e em outras mãos. Contudo, como não é sempre que os interesses e necessidades de determinados grupos são supridos devidamente pelo Estado ou pelos nossos representantes políticos. A partir desse conflito de interesses é que os movimentos sociais se tornam um instrumento de intervenção. Até o início do século XX, o conceito de movimentos sociais contemplava apenas a organização e a ação dos trabalhadores em sindicatos. Com a progressiva delimitação desse campo de estudo pelas Ciências Sociais, sobretudo a partir da década de 1960, as definições, embora ainda continuassem imprecisas, assumiram uma consistência teórica, para quem os movimentos sociais seriam o próprio objeto da Sociologia. Apesar do desenvolvimento que o conceito teve nos últimos anos, não há consenso ainda hoje entre os pesquisadores sobre seu significado. Isso sinaliza para a necessidade de uma maior discussão acerca da validade conceitual do termo, mesmo porque ele vem sendo utilizado indiscriminadamente para rotular qualquer tipo de associação civil.
As lutas sociais conferem aos movimentos um caráter circular. Eles vão e voltam segundo a dinâmica do conflito social, da luta social, da busca do novo ou da reposição e ou permanência do velho. Esses fatores impõem às ações dos movimentos caráter reativo, ativo ou passivo. Elas têm que se traduzir em demandas, que por sua vez poderão se transformar em exigências, por meio de uma ação coletiva. Os fatores carências, legitimidade da demanda, poder político das bases, cenário conjuntural do país darão a força social de um movimento, gerando o campo de forças do movimento social e uma dada cultura política.

\section{METODOLOGIA}

Este artigo é metodologicamente um estudo qualitativo de revisão da literatura narrativa. Os artigos de revisão narrativa são publicações amplas, apropriadas para descrever e discutir o desenvolvimento ou o "estado da arte" de um determinado assunto, sob ponto de vista teórico ou contextual. (Bernardo WM, et al, 2004; 50(1):1-9.) A revisão foi feita a partir de livros, monografias, teses, dissertações e artigos. As revisões de literatura caracterizam-se pela análise e síntese das informações fornecidas por todos os estudos relevantes publicados sobre determinado tema, para sintetizar o corpo de conhecimento existente e concluir a conclusão sobre o tema de interesse. Mancini, Marisa Cotta, e Sampaio, Rosana Ferreira. (2006). Considera-se que todo processo de pesquisa científica começa com um problema, dúvida ou dúvida, o que motiva o pesquisador a buscar informações sobre determinado tema em bibliotecas e / ou bases de dados bibliográficos digitais. (TASCA et al., 1999). Dessa forma, os autores da pesquisa entendem que tal escolha metodológica constitui a contribuição científica mais adequada, no momento, para o tema investigado.

Os temas da organização e do trabalho foram ganhando também relevância, no próprio processo de construção daquela consciência. Sabemos que o método Paulo Freire foi aplicado originalmente em programas de alfabetização de jovens e adultos da área rural do Nordeste e ampliou-se para todo o território nacional, entre junho de 1963 e o golpe militar de março de 1964; a partir dos anos 70, ele foi aplicado em várias regiões do mundo em "trabalhos de base" em geral. Recordamos que o método consistia em três momentos básicos: a investigação temática que consistia na busca de palavras e temaschave no universo vocabular do(s) aluno(s) e da sociedade onde vive(m); a tematização, com a codificação e ou decodificação desses temas e ou palavras e seu significado social e a problematização da busca de superação das primeiras impressões por uma visão crítica. Destacamos que uma das maiores inovações do método de Freire, quando surgiu e também atualmente, é o fato dele ter como base o diálogo. Portanto, nos anos 60, quando o método foi elaborado, ele era moderno e avançado para sua época, pois dava grande ênfase aos processos comunicativos. Sabe-se que o tema da comunicação entrou na agenda contemporânea da comunidade dos acadêmicos e dos planejadores públicos como "obrigatória" apenas nos anos 80 , dado o avanço dos meios de comunicação, novas tecnologias e o papel da mídia. Para Freire, "o diálogo consiste em uma relação horizontal e não vertical entre as pessoas implicadas" (GADOTTI, 1999, p. 9). A reflexividade - tão aclamada nas teorias dos anos 90 - já estava colocada no método de Freire na medida em que o oprimido só se liberta quando adquire a capacidade de refletir sobre as condições de sua própria vida e conquista autonomia para realizar seu destino histórico.

A pedagogia do diálogo redefiniu a relação pedagógica na medida em que redefiniu a relação entre o professor e aluno, e ou, educador e educando. O professor é visto por Freire como alguém ao lado do aluno, um ser que também busca e também aprende; o aluno passa a ser sujeito das ações educativas e não mais objeto, ganhando dignidade no processo educativo. As experiências de Freire no Chile e na Guiné Bissau, ao final dos anos 60 e nos anos 70, foram decisivas para a redefinição de algumas de suas concepções iniciais, que destacavam mais as ações - culturais e problematizadora - como 
geradoras da consciência. Freire chamou a atenção dos educadores na primeira fase do método, quando se procura descobrir o universo vocabular do grupo - para que atente tanto para as palavras carregadas de sentido existencial (cunho emocional) como para outras experiências típicas da vida cotidiana dos educandos, expressas por "formas de falar particulares, palavras ligadas à experiência do grupo, especialmente à experiência profissional" (FREIRE, 1979). Portanto, para Paulo Freire, a conscientização não significa um ato mecânico, instantâneo, de tomada de consciência da realidade. Ela é um processo construído por momentos onde se caminha do nível espontâneo e ingênuo, que ocorre quando a pessoa se aproxima da realidade, para uma tomada de consciência. A conscientização não pode existir fora das "práxis", ou melhor, sem o ato ação reflexão. Por isso mesmo, a conscientização é um compromisso histórico. É também consciência histórica: é inserção crítica na história, implica que os homens assumam o papel de sujeitos que fazem e refazem o mundo. A conscientização não está baseada sobre a consciência, de um lado, e o mundo, de outro; por outra parte, não pretende uma separação. Supõe, por sua vez, o superar a falsa consciência, quer dizer, o estado de consciência semi-intransitivo ou transitivo ingênuo, e uma melhor inserção crítica da pessoa conscientizada numa realidade desmitificada (FREIRE, 1980).

\section{ANÁLISE E DISCUSSÃO}

Cumpre aqui se registrar que estas expressões organizativas mobilizam grupos específicos, levantam bandeiras bem definidas, apresentam formas diversas de mobilização, conseguindo consistência cada vez maior, construindo teias de articulação às vezes invisíveis e redes de comunicação e solidariedade responsáveis por importantes conquistas. Entre estas podemos destacar quatro condições que são fundamentais na Educação Popular e na Inclusão Social: Autoconfiança pessoal e solidariedade social, muita gente confirma que passou a se valorizar mais, a se amar mais, a defender sua dignidade humana, a partir de sua participação em alguma forma de organização popular; Modificações no poder local e deslocamentos na política tradicional, como o avanço na capacidade de intervenção dos movimentos tem provocado importantes e visíveis mudanças locais, como a participação em Conselhos de Gestão em políticas públicas, eleição de parlamentares oriundos de processos reivindicatórios e que se formaram na luta popular; Avanços nas condições de existência e mesmo garantia de sobrevivência de expressivos grupos populares no país - muitas pessoas têm acesso à terra para trabalhar, à casa para morar, à água para beber e para a higiene doméstica, a serviços públicos de saúde, de educação, de atendimento à criança, ao adolescente, aos idosos, aos portadores de deficiência, porque elas se mobilizaram através de seus movimentos organizados; e por fim, mas não menos importante, a consciência de direitos e exercício da cidadania. Podemos intuir que os Movimentos Sociais são de extrema importância, porque cobram mudanças, reivindicam transformações, despontam quando a povo não está satisfeito com as medidas adotadas por governantes, além de cobrar medidas quando indispensável. A mobilidade social serve como insumo às suas constituições, inclusive da cidadania. Sem a atividade de nossa sociedade, não existiram seus respectivos produtos finais, como a ética, a moral, enfim, todos os valores consagrados dela. Os movimentos sociais clássicos se constituíram especialmente em torno das lutas dos trabalhadores desde a consolidação do capitalismo, travam fortes embates políticos com o Estado porque buscam transformações na estrutura econômica e social para superar as condições de opressão da classe trabalhadora, tanto no campo quanto na cidade. Resumindo: Pretendem assumir o controle do Estado ou, ao menos, transformar sua estrutura. Os movimentos sociais tradicionais também podem ser identificados por suas demandas, como as dos trabalhadores por melhores salários, melhores condições de trabalho, redução da jornada e estabilidade de emprego, dos grupos que se organizaram na luta por moradia, infraestrutura de saneamento, habitação, transporte público ou educação, educação em saúde que pode ser pensada, como instrumento para alicerçar o princípio da integralidade, no campo da estruturação do Sistema Único de Saúde
(SUS), permitindo a garantia da participação popular nas políticas públicas de saúde e englobar conhecimentos de prevenção, promoção e terapêutica, potencializando o controle social destas políticas públicas buscando-se o pleno atendimento às demandas da população (AMEIDA, 2016). De uma forma geral, apesar da politização geral que as ações propiciaram em passado recente, havia muitos problemas porque os indivíduos e grupos, sob a ação da Educação Popular, permaneciam muito dependentes de seus articuladores, coordenadores, das redes que estruturavam os trabalhos, etc. Poucos, de fato, atingiam a autonomia no pensar e no agir, ainda que, no conjunto, o resultado tenha sido grande em termos de ganhos sociopolíticos, no sentido da conquista de espaços democráticos na sociedade civil e política. De fato, não havia horizontalidade entre os participantes - não o tipo de horizontalidade a que aludem os revisores da Educação Popular, centrada na relação professor e o aluno e ou educador e educando. A não horizontalidade estava basicamente entre os que programavam as ações e os que as executavam na base. Entre a base e os articuladores nacionais/estaduais ou locais - e os outros membros da rede associativista. As hierarquias de poder nem sempre eram formais, mas usualmente informais. Mas todos as conheciam e as vivenciavam.

Abordamos os meandros dos movimentos sociais brasileiros sob a perspectiva do educador Paulo Freire, apontando a Pedagogia da Libertação como instrumento a serviço da transformação social. Em uma época de pessimismo vigente na sociedade capitalista, Freire propõe a educação como uma possibilidade de conscientizar os sujeitos de sua condição de oprimido, avançando para uma resistência a grupos e forças que tentam prevalecer às orientações dominadoras. As resistências sociais frentes às forças opressoras de acordo com as perspectivas de Freire, convertem-se em movimentos sociais que se eclodem em toda a sociedade brasileira. Apresenta-se também os principais movimentos sociais em vigência no Brasil, especialmente, Movimento dos sem-terra, a luta da mulher pela igualdade de gênero entre outros. Além disso, aponta-se ainda as discussões mais recentes dos movimentos sociais no campo político, sendo temática das eleições presidenciais brasileiras ocorridas em outubro de 2016. A discussão empreendida indica que é um desafio gigantesco ao sistema educacional brasileiro atender um ensino que valorize a participação social que incentive cada brasileiro a adquirir conhecimentos para lutar por sua liberdade, uma vez que a educação brasileira se pauta na reprodução da sociedade de classe, onde o conhecimento se coloca como o próprio instrumento de dominação a serviço de interesses hegemônicos.

Em última análise, a Pedagogia Libertadora de Freire não é uma postulação apenas para o contexto da sociedade brasileira, mas também é um convite para todos os excluídos da história, para aqueles que estão à margem da sociedade, pois a compreensão crítica dos fatos, aliado à utopia da mudança, leva-nos a entender que mudar é difícil, mas possível. Trata-se, portanto, de uma busca incessante pela libertação que se pode efetivar por meio das mobilizações sociais, nesse sentido, o conhecimento, a cultura e a história são produtos humanos que se transformam permanentemente a partir de ação humana sobre o mundo, compreendendo, desse modo, o sentido da humanização. Em síntese, Paulo Freire (1987) deixa um incentivo a todos os que acreditam na libertação dos oprimidos: "Vivam por mim, já que eu não posso viver a alegria de trabalhar com crianças e adultos, que com sua luta e com sua esperança estão conseguindo ser eles mesmos e elas mesmas". Além disso, o autor alerta que se de todos os pensamentos, postulações e contribuições ao campo da pedagogia nada ficar, que ao menos permaneça a esperança e a confiança nos homens. Através de contribuição de Paulo Freire, é possível compreender a história humana como uma possibilidade e não como uma determinação. Nesse sentido, a ação do homem atua como sujeito da história, uma pessoa que pode intervir no mundo através de sua ação consciente. Dessa forma, a Pedagogia da Libertação de Paulo Freire se apresenta como uma ferramenta fundamental no processo de sensibilização e de constituição dos movimentos sociais. Nota-se que não é a condição de opressão e da própria exclusão que leva as pessoas a se envolverem em lutas sociais, mas a compreensão da lógica do seu estatuto de oprimidos, da compreensão crítica dos fatos que permite com que essas pessoas 
sejam conscientes favorecendo, assim, o início pelo processo de luta por melhores condições de vida.

\section{CONSIDERAÇÕES FINAIS}

Este processo de conscientização, proposto por Paulo Freire, é, portanto, presente na composição dos movimentos populares, numa educação sócio-trasnformadora e inclusiva, e o reconhecimento desta educação e a sua condição permite a criação de espaços de reflexão e manifestação que se transforma em uma denúncia da práxis da realidade cruel e anúncio de uma nova concepção de sociedade. Neste processo, Freire ressalta a importância da educação dos homens em uma devotada metodologia de criação e recriação do seu conhecimento, a sua cultura e do mundo em que vive, nesse sentido, a educação sozinha não pode transformar a sociedade, mas, também, sem educação, a sociedade não pode vislumbrar processos de mudanças. A provocação, portanto, está no avanço das práticas educativas, a fim de orientá-las para a busca de uma ação constante crítica na sociedade e na formação de sujeitos críticos prontos para agir em busca de um mundo melhor. Acercando-se a educação popular, da periferia, do campo, de gênero e a feminista, partindo dos pressupostos da educação popular comprometida com a educação libertadora e transformadora dos sujeitos e, ainda, em diálogo com o feminismo, aproximar da constituição de uma proposta política de educação, de uma nova pedagogia. Por educação popular entendemos "aquela que é produzida pelas classes populares ou para as classes populares, em função de seus interesses de classe", conforme Brandão (1987, p.63). Segundo ele, uma "educação feita de acordo com os interesses das classes populares". De acordo com esta concepção de educação, o cerne do processo educacional está diretamente relacionado aos saberes diferenciados de cada educanda ou educando. Enquanto processo educativo, no bojo da conscientização e na transformação dos processos educativos, também existem as TEs (Tecnologias Educativas) com todas as suas potencialidades, como pode se destacar a TE Teatro e Dinâmica Verdade ou Mito no município de Juazeiro do Norte, desenvolvendo a partir do Programa de Saúde na Escola, espaço de aprendizagem e socialização em que a teoria da enfermagem é adequada ao contexto do Nordeste brasileiro e que possibilita a participação da Comunidade Local e que são os usuários finais que usufrui do processo de ensino aprendizagem (GERMANO, SNF. et al. 2020, p.07). Acredita-se que o ato educativo se dá na relação dos agentes e ou grupos populares. E este ato é passível de ser educativo na medida em que ambos os parceiros têm saberes diferenciados.
Tem formas diferentes e graus diferentes, entendendo "a educação popular como o esforço de mobilização, organização e capacitação das classes populares; capacitação científica e técnica" (FREIRE, 2001, p.19). Nessa direção, a definição de educação popular é que ela é um modo de conhecimento que parte da prática política, ou seja, o conhecimento do mundo também é feito através das práticas do mundo; e é através dessas práticas que inventamos uma educação familiar às classes populares. Finalizando, como bem já escreveu Paulo Freire, há jeitos de apreciar o mundo e as classes populares têm um modo peculiar de conhecimento.

\section{REFERÊNCIAS}

Almeida TG. et al. 2016. Validação de material educativo como ferramenta pedagógica sobre métodos contraceptivos para adolescentes. Rev. Enferm. UFPE, 10(12): 4696-700.

Bernardo WM, Nobre MRC, Jatene FB. 2004. A prática clinica baseada em evidências. Parte II: buscando as evidências em fontes de informação. Rev Assoc Med Bras. 2004; 50(1):1-9.

Brandão, Carlos. A questão política da educação popular. $7^{\mathrm{a}}$ ed. São Paulo: Editora Brasiliense, 1987.

Freire, Paulo. Pedagogia do oprimido. 17. ed. Rio de Janeiro: Paz e Terra, 1987.

Freire, Paulo. Que fazer: Teoria e Prática em Educação Popular.6 ${ }^{\mathrm{a}}$ edição. Petrópolis: Vozes, 2001.

Gadotti, M. Convite à leitura de Paulo Freire. São Paulo: Scipione, 1999

Germano, SNF. et al. 2020. Tecnologias educacionais aplicadas à saúde sexual e reprodutiva dos adolescentes de escolas públicas. Revista Eletrônica Acervo Saúde, 2020; 12(11)

Gohn, Maria da Glória. 1997. Os sem-terra, ONGs e cidadania. São Paulo: Cortez.

Mancini, M. C. \& Sampaio, R. F. 2006. Quando o objeto de estudo é a literatura: estudos de revisão. Brazilian Journal of Physical Therapy, 10(4). Recuperado de https://dx.doi.org/10.1590/S141335552006000400001

Werneck, H. Se você finge que ensina, eu finjo que aprendo. 16 ed. Petrópolis: Vozes, 1999.

Tasca, J. et al. 2010. An approach for selecting a theoretical framework for the evaluation of training programs. Journal of European Industrial Training, v. 34, p. 631-655. 